\title{
A CONTINUIDADE DA ABORDAGEM POSITIVISTA ACERCA DO FOLKLORE NA OBRA DE THÉO BRANDÃO
}

\section{THE CONTINUITY OF THE POSITIVIST BOARDING CONCERNING THE FOLKLORE IN THE WORKMANSHIP OF THÉO BRANDÃO}

Gabriel Magalhães Beltrão*

\begin{abstract}
Resumo: $O$ presente artigo se propõe a analisar a abordagem que o folclorista alagoano Théo Brandão tem a respeito do folklore. Partindo-se do pressuposto de que o folclorista perspectiva o seu objeto de estudo a partir do conjunto de valores intrinsecamente relacionado à sua posição social numa sociedade capitalista retardatária, no caso a alagoana, evidencia-se que a sua concepção acerca do folclore está profundamente marcada pela necessidade de representação do existente bem como do seu devir - que satisfaça às elites locais em vias de modernização. Para estes fins, o resgate da abordagem positivista do fenômeno folclórico se mostra bastante profícuo à medida que separa por um hiato profundo o homem do povo - agente per excellence das expressões folclóricas - da modernidade em voga. Tal absorção do positivismo tem também implicações epistemológicas: o caráter sui generis do objeto folclórico reside precisamente na sua falta de encadeamento causal com a realidade moderna, logo, a atividade do folclorista deve se limitar ao trabalho descritivo, prescindindo de objetivos heurísticos.
\end{abstract}

Palavras-chave: Folclore, positivismo, formação capitalista, representação.

Abstract: The aim of this text is to analyse Theo Brandão's approach concerning folklore. It is presupposed that the folklorist from Alagoas has a point of view about his object of study due to a set of values, intrinsically related to the social position he occupies in a backward capitalist society, in the case, the one from Alagoas. It is evident that his concept of folklore is deeply characterized by the need for representation of the existent - as well as what it is to come - whom satisfies the modernising local elites. For these purposes, the retaking of positivist approach on the study of folkloric phenomenon is very useful as it separates by a yawning hiatus the man of the people - agent per excellence of the folkloric expressions - from the current modernity. This assimilation of positivism also has epistemological implications: the sui generis character of folkloristic object consists in its lack of causal nexus with modern reality, therefore, the folklorist activity is restricted to descriptive work, putting heuristic objectives aside.

Keywords: Folklore, positivism, capitalist formation, representation

O seguinte artigo a respeito do intelectual folclorista Théo Brandão é fruto do projeto de iniciação científica que anseia trazer à tona os precursores das Ciências Sociais no Estado de Alagoas. A partir deste mote é que se torna de fundamental importância a análise do referido autor, pois este foi um dos que iniciaram a institucionalização das Ciências Sociais em Alagoas a partir do antigo curso de Estudos Sociais - predecessor direto do curso de Ciências Sociais da Universidade Federal de Alagoas - onde ministrava a disciplina Antropologia Física.

Apesar de possuir um caráter também historiográfico, não é este o foco central da nossa empreitada: buscamos primordialmente realizar uma análise sociológica da intelligentsia a partir das orientações dadas por Michel Löwy em A Evolução Política de Lukács: por uma sociologia dos intelectuais revolucionários. Ou seja, buscaremos explicitar quais os vínculos do pensamento de Theo Brandão com a sua realidade sócio-histórica, tomando a sua abordagem a respeito do folclore como 0

\footnotetext{
* Bacharel em Ciências Sociais pela Universidade Federal de Alagoas/UFAL onde em 2008 integrou o Núcleo de Memória das Ciências Sociais em Alagoas, coordenado pela professora doutora Alice Anabuki que buscava trazer à tona os intelectuais precursores das Ciências Sociais no Estado de Alagoas.
} 
fulcro para desvendar tais relacionamentos contidos no seu pensamento que aparece supostamente independente a uma leitura apressada.

\section{1 - 0 folclore numa abordagem positivista}

Os pensamentos científicos positivista e evolucionista de Augusto Comte e Spencer, respectivamente, apregoam a ideia de que a sociedade burguesa se configura enquanto o ápice da evolução humana, estágio evolutivo marcado pela razão em contraposição ao saber tradicional. Assim, a modernidade é identificada com o saber racional característico da ciência que teria suplantado as formas empíricas de conhecimento identificadas ao arcaico, ao tradicionalismo, ao pré-moderno. Instaura-se com esses autores uma abordagem dicotômica das sociedades ocidentais: apesar de terem atingido o momento último da evolução, estas sociedades ainda trazem consigo reminiscências arcaicas que estariam, inelutavelmente, em vias de desaparecimento. Haveria uma natureza distinta entre as formas de ser, de existir e de pensar, associadas às camadas populares, a todo aquele conjunto formado por proletários e camponeses que estão desprovidos de uma cultura moderna1, racional, e que, ao contrário, se caracterizam pelas relações pessoais, pelo saber empírico, pela cultura oral, pela produção própria de utensílios como os brinquedos, etc. A burguesia, no entanto, era a representação clara da modernidade e do progresso à medida que suas relações são impessoais intermediadas pelo dinheiro - , sua cultura é culta (erudita) marcada pela escrita e pela intencionalidade autoral.

Surge dessa abordagem, o espaço para uma nova ciência típica da modernidade: aquela que tem por objeto específico o saber popular. Havia nas sociedades civilizadas uma cultura arcaica que sobrevivia no interior da modernidade apesar de nada ter a ver com ela. Justamente esse saber popular que se encontra à margem do civilizado é que seria o objeto sui generis responsável pela emersão da ciência de saber popular - o folclore. Sobre essa pretensão diz Florestan Fernandes em um dos seus muitos escritos sobre o folclore:

Em síntese, o objeto do folclore seria - pode-se dizer assim, dentro desse esquema - 0 estudo dos elementos culturais praticamente ultrapassados: as "sobrevivências". Ou seja, como o definiu Sébillot: "a ciência do saber popular", partindo da significação do próprio vocábulo (folk = povo; lore = saber), tal como propusera o seu criador, William Thoms. Essa é a pista seguida por Saintyves na definição que apresentou mais tarde e que logo se tornou

\footnotetext{
1 Diz Florestan Fernandes: "Para os autores da época e ainda para alguns contemporâneos o termo cultura significaria o patrimônio cultural das classes mais elevadas; e seria, caracteristicamente, uma cultura transmitida por meios escritos, compreendendo todos os conhecimentos científicos, as artes em geral e a religião oficial. 0 termo folclore significaria e abrangeria, pois, todos os elementos que constituem o que se poderia entender 'a cultura das classes baixas', transmitida oralmente. Aqui começou a série de analogias e termos de comparações entre os 'meios populares' e os 'primitivos', no folclore, ambos considerados povos pré-letrados ou 'incultos', isto é, gente sem a cultura das classes 'superiores'". (Fernandes, Florestan, 1920-1995. O folclore em questão/ Florestan Fernandes. $-2^{\mathrm{a}}$ ed. - São Paulo: Martins Fontes, 2003. - Raízes. Pg.39 nota 1)
} 
clássica, principalmente entre os folcloristas latinos: "o folclore é a ciência da cultura tradicional dos meios populares dos países civilizados". (FERNANDES, F. 2003, Pg. 41)

Ao folclore enquanto ciência cabe a tarefa de descrever e sistematizar tudo que estiver relacionado à cultura popular, o que gera uma distinção da atividade do folclorista em relação às demais ciências sociais. Por partir do pressuposto de que o folclore é uma mera reminiscência, o folclorista não busca realizar explicações causais a respeito do conteúdo dos fatos folclóricos, ou seja, não há qualquer pretensão de desvelar o relacionamento dos fatos folclóricos com a totalidade social na qual eles estão inseridos. Essa abordagem meramente descritiva faz bastante sentido à medida que o pressuposto teórico é proveniente do positivismo que encara o folclore como um anacronismo em vias de desaparecimento. Algo que é anacrônico é retrogrado e estranho ao moderno e, por sua vez, não possui grandes significados sócio-culturais já que não se relaciona com a modernidade em voga.

Os antropólogos e sociólogos não comungam desta ideia e vêem o folclore inserido "numa ordem de fenômenos mais ampla - a cultura - e podem ser estudados como aspectos particulares da cultura de uma sociedade" (idem, pg. 48); qualquer que seja a fundamentação teórica do sociólogo ou do antropólogo o folclore sempre será encarado como um conjunto de manifestações culturais específicas, mas que está em conexão com a sociedade como um todo não havendo essa dicotomia típica dos folcloristas. Finalizando, diz F. Fernandes sobre a maneira distinta como a sociologia e a antropologia enxergam os fatos folclóricos:

Os fatos folclóricos não passam de um aspecto da cultura totalmente considerada e são fatos que se referem a modalidades diferentes dessa cultura e, por conseguinte, só podem ser explicados a partir dessa mesma cultura. (Idem, pg. 49)

\section{1 - A continuidade de Theo Brandão}

Dito essas considerações a respeito da concepção positivista clássica do folclore, buscaremos agora demonstrar a vinculação de Théo Brandão com a mesma. Segundo Florestan Fernandes, a busca incessante inicial por consolidar o folclore como ciência particular mediante as discussões teóricas foi suplantada por uma nova geração menos afeita a essa discussão e mais interessada em realizar trabalhos descritivos. Dessa forma, a tradição folclorista da América Latina se interessava quase que exclusivamente pelo trabalho de campo, pela descrição das manifestações populares e pela busca da origem de tais manifestações, eximindo-se totalmente de explicações causais destes fatos folclóricos. Tratava-se de estudos "biográficos" de determinados elementos folclóricos, como gosta de dizer F. Fernandes.

A obra folclorista do médico de formação e alagoano Théo Brandão se insere na concepção teórica positivista e neste contexto prático característico da América Latina por vários fatores que 
tentaremos enumerar a partir de agora. Em palestras ao Rotary Club em 1949, Théo Brandão assim define o folclore:

\begin{abstract}
Folclore, segundo o mais recente conceito enunciado por André Varagnac é civilização tradicional, isto é, engloba todos os elementos culturais não elaborados intelectualmente, tudo aquilo que o homem, de qualquer nível social aprendeu fora dos livros, da escola e dos diversos meios de difusão cultural: o fonógrafo, o cinema ou o rádio. ${ }^{2}$
\end{abstract}

O folclore é claramente definido como civilização tradicional, ou seja, como aquela parcela da cultura que está distanciada da modernidade, que é externa e estranha aos mecanismos modernos da cultura, tal como a escola, o cinema e o rádio - locus do saber racional. 0 tradicional é definido como os elementos culturais não elaborados intelectualmente à medida que possui um caráter diretamente empírico, desprovido de sistematização conceitual, e é propagado mediante a oralidade e não através da escrita.

O homem de qualquer nível social está inscrito nesta parcela tradicional, arcaica, sendo este reconhecimento de Théo Brandão bem característico da nossa formação capitalista hiperatrasada, na qual a inexistência de ruptura histórica ocasiona sempre processos marcados pela sobrepujança da continuidade sobre as descontinuidades: mesmo as nossas elites agro-exportadora e mercantil portadoras por excelência da modernidade - trazem consigo marcas inelutáveis do tradicional. Apesar dessa constatação de que o arcaico não é exclusivo ao povo no estado de Alagoas, em uma passagem da sua monografia, Reisado Alagoano, Théo Brandão diz implicitamente que a modernidade é uma exclusividade das nossas elites. Diz, referindo-se ao reisado:

\begin{abstract}
E quando em vilas ou cidades não encontram casa que os aceitem para dançar (o que é muito mais comum hoje do que antigamente, quando a aristocracia rural dos bangüês e a classe média das cidades do interior a ela ligada ainda não possuíam, nem rádios, nem vitrolas, nem cinemas e era a grande apreciadora das folganças populares) realizam os folguedos nos mercados públicos. Ou então, se algum chefe político ou pessoa influente da localidade patrocina a exibição, ela se realiza em armazéns, pátios cimentados, galpões e não mais nas salas de visita ou de jantar como acontecia nos tempos antigos. (BRANDÃO. T. Reisado Alagoano, pg.26)
\end{abstract}

O tom nostálgico da passagem não encobre 0 fato de que nela podemos identificar a associação da modernidade à aristocracia rural do Estado, aquela responsável pela adoção de valores culturais modernos que deixam para trás o tradicional reisado. Ao homem do povo resta a continuidade das suas manifestações culturais tradicionais, a partir de agora não mais valoradas pelos "senhores do tempo" que trazem para o mesmo espaço geográfico a modernidade dele (do povo) excluída. $\mathrm{O}$ arcaico

\footnotetext{
2 Palestra ministrada ao Rotary Club em 1949; coletada no Instituto Histórico e Geográfico de Alagoas e extraída do livro Folclore de Alagoas/Maceió - Alagoas (1949).
} 
pode até respingar na elite agro-mercantil alagoana, no entanto, a modernidade é vista como uma exclusividade desta, tornando-se o povo reprodutor por excelência da cultura tradicional; a este a modernidade é estranha assim como o é a sua processualidade, seu devir.

Seguindo a tônica positivista, ao homem do povo é excluída a sua participação no moderno e sua cultura passa a ser etiquetada como um anacronismo exótico que deve ser descrito e sistematizado por uma área específica do saber - o folclore como ciência do saber popular. Temos que ressaltar aqui, entretanto, uma tênue distinção de suma importância. Nas sociedades que atingiram o capitalismo pela via clássica - Inglaterra, França e Estados Unidos -, evidenciou-se uma transformação abrupta em toda a sociedade onde os elementos pré-capitalistas foram rapidamente substituídos por um conjunto de práticas e valores essencialmente distintos. Neste contexto, há até um certo sentido em se dizer que os aspectos tradicionais são anacrônicos, meras reminiscências, justamente pelo fato de que tais práticas e valores serão em um curto prazo suplantados por aqueles plenamente capitalistas. Este não é o caso da formação brasileira, especificamente da sub-região representada por Alagoas. Não seria nem um pouco plausível a Théo Brandão afirmar explicitamente tal como faziam os propagadores da concepção positivista clássica - que a cultura popular é um anacronismo existente na sociedade alagoana, afinal, longe de estar em vias de dissolução, ela faz parte intrinsecamente da nossa modernidade capitalista.

A nossa formação capitalista traz consigo elementos eminentemente pré-capitalistas que fazem parte do próprio desenvolvimento do capital local: não se trata de uma relação dicotômica, mas, ao contrário, de uma unidade dialética na qual o velho se sintetiza ao novo como forma de potencializálo - no caso potencializar a exploração capitalista. Diante disso, Théo Brandão absorve a perspectiva teórica que taxa a cultura popular como isenta da modernidade e numa relação de externalidade em relação a ela, mas com uma sutil diferença em relação ao positivismo clássico, visto que o arcaico aqui não está em vias de dissolução e por isso, o sentido mais puro do ser alagoano deve residir precisamente neste tradicionalismo.

Enquanto numa França revolucionária o referencial identitário reside nos valores tipicamente modernos, para Théo Brandão a identidade alagoana se encontra nas suas tradições culturais mais apartadas da modernidade - especificamente no reisado e no guerreiro.

Poderíamos dizer, então, que há um positivismo velado na abordagem de Théo Brandão sendo este justificado pelas especificidades sócio-históricas da nossa formação capitalista. Uma reprodução em mesmo tom desta abordagem de origem francesa na peculiaridade da nossa formação não possibilitaria que o nosso autor lograsse êxito na sua empreitada de formular uma interpretação da identidade alagoana que se tornasse hegemônica. Afinal, o seu objetivo foi tão bem realizado que a bandeira de Alagoas foi substituída pela sua proposta que está diretamente voltada à exaltação das 
tradições culturais alagoanas. A bandeira do Estado estaria representando a "essência" do povo alagoano, aquilo que é mais próprio à nossa identidade, mesmo que esta resida numa dimensão da sociedade que é alijada da modernidade; talvez seja justamente por este distanciamento quase que absoluto existente entre a cultura popular e a modernidade que as manifestações tradicionais sejam entronadas como a nossa essência última. Por este fato é que se evidencia uma certa repulsa quanto ao movimento interno de transformação existente no folclore; diz Théo Brandão:

\begin{abstract}
Atualmente, a preocupação com os improvisos de "peças" e com as intermináveis "embaixadas", do mesmo modo que a lei do menor esforço que não se coaduna com 0 tirocínio e a virtuosidade necessários à aquisição da antiga técnica do bailado, levam ao abandono dos "passos" difíceis e por isto mais belos, substituídos por danças mais simples que requerem muito menor esforço e por uma independência de movimentos, uma descoordenação do todo que, embora não deixe de ter seus atrativos, não se pode comparar com a uniformidade e a precisa marcação dos antigos reisados. (Idem, pg.76)
\end{abstract}

O hiato entre o popular e o moderno não é absoluto e, por isso, evidenciam-se as transformações no interior do folclore, mesmo que a contragosto do folclorista. Apesar dessas modificações, ao folclorista não cabe a tarefa de entendê-las, explicá-las, mas, tão-somente, descrevêlas e, principalmente, remeter-se às origens destas manifestações para daí apreender a sua essencialidade que não se perde com esses movimentos pontuais, que apenas aparentemente são degeneradores. Desta essencialidade é que provém a nossa identidade que nos distingue dos demais povos da Federação.

Como já havia dito anteriormente, o caráter dicotômico da perspectiva positivista a respeito do folclore conduz à defesa do folclore como ciência do saber popular e, por se tratar de um anacronismo, tal ciência estaria isenta do caráter explicativo causal existente nas demais; afinal, pensar o folclore é pensar uma cultura que, por mais que defina a nossa identidade, não tem vínculos com a modernidade em voga, não havendo a necessidade de se buscar explicá-la à luz da sociedade tomada como um todo.

Théo Brandão faz uma crítica às abordagens teóricas que abandonam a busca pelas origens do folclore em prol da compreensão da sua função no contexto cultural; diz ele no artigo Influencias Africanas no Folclore Brasileiro:

Demais, tem contribuído fortemente para que se tornem mais árduas essas dificuldades, a ausência, nos últimos anos, de interesse, valoração e prestígio para os estudos genéticos no folclore, e conseqüente abandono da pesquisa das influencias e fontes de nossas tradições populares. Dominam entre folcloristas as teses funcionalistas e aculturacionistas segundo as quais é ociosa e contraproducente o estudo das fontes e origem dos nossos costumes e do nosso folclore, o seu estudo cientifico interessa-se por sua função no contexto cultural ou pelas modificações por eles sofridas em nossa sociedade e cultura, em face da interação com outros fatos e costumes autóctones e alienígenas. 
Théo Brandão quer um estudo que se atenha à busca pelos elementos genéticos do folclore, buscando trazer à tona as influências múltiplas que contribuíram à formação do folclore alagoano; em outras palavras, busca-se a "essência" das nossas tradições culturais que formam a nossa identidade alagoana.

Por mais que o folclore sofra um processo de transformação - seja por fatores exógenos ou endógenos à sociedade alagoana - isso não é o que deve interessar ao folclorista, cabendo a este trazer à tona a pureza do tradicional que não se perde nas transformações modernizadoras. Não cabe também ao folclorista buscar desvendar qual a função do folclore no interior da sociedade, afinal este objetivo nunca foi - desde as abordagens clássicas - próprio ao folclore enquanto ciência; "é preciso procurar as origens, antes que as causas"3, num claro objetivo "biográfico" dos fenômenos folclóricos.

Pode-se dizer que a essência alagoana contida no folclore possui um caráter metafísico, visto que esta passa incólume por todas as transformações sofridas pelo próprio folclore enquanto complexo social partícipe da totalidade social; ou seja, Théo Brandão opera uma reificação da identidade alagoana ao atribuí-la uma dimensão essencial metafísica. ${ }^{4}$

Essa carência explicativa na obra de Théo Brandão - advinda, segundo a nossa hipótese, da sua filiação teórica com a abordagem positivista a respeito do folclore - foi notada por Florestan Fernandes que teceu os seguintes comentários a respeito da sua premiada obra O Reisado Alagoano:

\begin{abstract}
A monografia do sr. Théo Brandão sobre o "O Reisado Alagoano", contemplada com o primeiro prêmio, distingue-se pela documentação extraordinariamente rica, quase toda inédita e exposta de maneira minuciosa, clara e objetiva. 0 autor teve 0 cuidado de indicar 0 local e a data em que foram colhidos os textos, as melodias e outros dados. Interessantes e valiosas são as informações sobre as mudanças sofridas pelo "reisado" no decorrer do período a que se refere a pesquisa do autor. Pena é que o sr. Théo Brandão não tenha procurado elaborar cientificamente 0 excelente material que apresenta. A análise etnográfica não é completa, mas em muitas partes pelo menos satisfatória, ao passo que a discussão sociológica apenas se esboça em algumas passagens. Não há nenhuma conclusão geral do estudo. ${ }^{5}$
\end{abstract}

A obra é reconhecida pela sua capacidade de documentar o reisado alagoano, demonstrando uma série de modificações existente entre o reisado daquele período em relação ao reisado praticado

\footnotetext{
${ }^{3}$ Frase Maunier retirada do livro acima citado de Florestan Fernandes, pg. 60.

${ }_{4}^{4}$ Para evitar equívoco, deixa-se claro que a busca pelas origens de uma formação social não é necessariamente realizada mediante uma abordagem positivista - que isola um determinado complexo da totalidade social, como o folclore, identificando nele uma "essência" pétrea e inatingivel que não se transforma em função das mudanças evidenciadas na realidade social. Longe dessa universalização de uma essência hipostasiada, o materialismo histórico busca apreender a essência de uma formação social considerando-a historicamente, como produto de práticas sociais específicas. Refuta-se categoricamente 0 suposto abismo existente entre essência e fenômeno que hipostasia o primeiro e restringe a historicidade ao segundo; em suma, a realidade social nada mais é do que a articulação complexa existente entre esses dois momentos distintos igualmente históricos e que se unificam mediante uma série de mediações. Mais considerações sobre a relação essência-fenômeno ver em Lessa, S. Notas sobre a historicidade da essência em Lukács no link www.sergiolessa.com

${ }^{5} \mathrm{O}$ prêmio referido advém do $4^{\mathrm{a}}$ concurso de monografias sobre o folclore nacional instituído em 1949 pela discoteca pública municipal/SP.
} 
nos anos 20 e 30 - épocas em que o autor era neto de um senhor de engenho e adorava quando o seu avô aceitava que o reisado fosse realizado no interior da Casa Grande. Apesar desse reconhecimento, Florestan deixa claro as limitações do autor que não realiza uma elaboração científica do seu material, ou seja, não tem qualquer pretensão em compreender o sentido das manifestações culturais tradicionais para a sociedade alagoana, muito menos buscar explicações para as transformações evidenciadas no interior destas.

Feitas essas considerações que buscam provar a hipótese de que Théo Brandão dá continuidade à abordagem positivista a respeito do folclore, mesmo que com uma peculiaridade decorrente da nossa formação social específica, passaremos agora a uma nova etapa de caráter mais propriamente teórica. Nesta, anseia-se refletir a respeito da cultura, bem como sobre o papel dos intelectuais na formação de uma identidade regional; daremos ênfase ao reconhecimento de que a identidade é um espaço de conflito e que, consequentemente, não há interpretações acerca dela que não tenha uma determinada vinculação de classe. Em todo esse percurso terá a figura de Théo Brandão um papel central já que é dele que estamos tratando.

\section{2 - Cultura, formação da identidade regional e o papel dos intelectuais}

Quando se pensa a cultura normalmente se faz uma associação com os fenômenos subjetivos, com a dimensão das crenças e valores que diferenciam um povo de uma área geográfica específica dos demais povos, de maneira que estas representações imaginárias se consubstanciem em práticas sociais distintas. Dessa forma, toda e qualquer sociedade seria necessariamente cultura haja visto que todas possuem um conjunto de significados, signos e condutas peculiares que fundamentam a sua identidade, pressuposto indispensável ao sentimento de pertença e da alteridade. Certamente todo povo possui cultura, afinal é uma barbaridade etnocentrista se distinguir entre os povos de cultura e aqueles isentos de cultura. Todavia, a cultura que é própria ao ser social é entendida aqui como a complexa articulação existente entre subjetividade e objetividade, nunca numa abordagem que dissolva a objetividade na subjetividade. Isso significa dizer que as culturas dos povos não podem estar desconectadas das suas relações sociais objetivas, mas, antes, configuram-se precisamente na complexa articulação existente entre as práticas sociais primárias (o trabalho) e aquelas práticas sociais de caráter intersubjetivo (arte, folclore, direito, culinária, senso comum, etc.). É neste sentido que o sociólogo alagoano Golbery Lessa propõe a substituição do conceito de cultura - que se restringe à subjetividade - pelo conceito marxiano de práxis, pois neste caso busca-se elevar à consciência as múltiplas mediações que unificam os pólos distintos da subjetividade e da objetividade pondo um termo às abordagens culturalistas. Sobre essa perspectiva da cultura citemos Lukács: 
(...) tudo que a cultura humana criou até hoje nasceu, não de misteriosas motivações internas espirituais (ou coisa que o valha), mas do fato de que, desde o começo, os homens se esforçaram por resolver questões emergentes da existência social. É à série de respostas formuladas para tais questões que damos o nome de cultura humana. ${ }^{6}$

A cultura humana deve ser encarada como um conjunto de respostas que os homens já deram às demandas surgidas para a sua existência social, respostas estas que são dadas de acordo com as possibilidades historicamente existentes. Assim, o reisado alagoano descrito por Théo Brandão se configura enquanto uma resposta específica dada pelos sujeitos para expressarem, em termos estéticos a eles cabíveis, as suas realidades sócio-históricas peculiares. Torna-se, desta forma, uma manifestação historicamente fincada e que traz consigo todas as marcas características da formação social específica que fundamentou o seu engendramento pelos trabalhadores dos engenhos de cana de açúcar da província de Alagoas. Precisamente neste sentido diz Golbery Lessa, no artigo Outra Alagoanidade:

A alagoanidade não é só um fenômeno subjetivo, não é apenas um estado de consciência ou um jeito próprio de cada alagoano expressar sua individualidade, no sentido de possuir essas ou aquelas atitudes mentais. A alagoanidade é o conjunto articulado de sistemas que estruturam a formação social alagoana e possui singularidades em relação aos conjuntos análogos de outras formações sociais. ${ }^{7}$

A formação social alagoana possui peculiaridades que a distingue de outras formações, mesmo aquelas mais similares. Há, portanto, singularidades que distinguem, por exemplo, a nossa economia mesmo que seja em relação àquela existente em Pernambuco, que é bastante similar à nossa em função do nosso passado colonial; destas peculiaridades relacionam-se uma série de outras características que são próprias ao alagoano em outros complexos sociais, sem que com isso estejamos desconsiderando a autonomia relativa destes. Nas palavras de Golbery Lessa:

É fértil procurar no sistema econômico singularidades que são pólos de reprodução de singularidades de outros complexos da práxis alagoana. Isso não significa desprezar ou diminuir a importância da lógica interna de cada complexo social específico. (LESSA, G. Outra Alagoanidade, 2007).

Por tudo isso, nossa abordagem acerca do folclore pode ser definida como diametralmente oposta àquela proposta por Théo Brandão: estamos longe de considerar o folclore como uma manifestação cultural que não tenha nexos causais indissolúveis com a sua realidade sócio-histórica que fundamentou a sua emergência; nem muito menos achamos que tal manifestação cultural está isenta de movimentos internos que expressam as transformações da formação social alagoana. Por ser partícipe de uma totalidade social complexa, o folclore não pode em hipótese alguma ser considerado

\footnotetext{
${ }^{6}$ Citação extraída da dissertação de Ester Vaisman "O problema da Ideologia na Ontologia de G. Lukács" proveniente do livro de W. Abendroth Conversando com Lukács.

${ }^{7}$ Os grifos são meus.
} 
um anacronismo histórico que conviva à margem - em paralelo - da sociedade moderna; por mais que o seu surgimento nos remeta ao passado colonial, ele se transforma em consonância com o lento processo de transformação da sociedade alagoana, passando a conviver com o moderno não numa posição de externalidade dicotômica, mas numa relação de síntese dialética que unifica o que aparentemente se repele. ${ }^{8}$

É de fundamental importância que toda formação social busque promover uma consciência de si mesma, no caso de Alagoas, que haja uma interpretação acerca do ser alagoano que seja universalizada a todos aqueles que habitam este espaço geográfico específico. A interpretação a respeito desta realidade social peculiar não é um espaço harmônico como às vezes se propõe, mas, ao contrário, toda e qualquer interpretação que anseie delinear uma identidade cultural traz consigo as marcas do seu ponto de vista de classe. Além disso, propor uma interpretação sobre a identidade de um povo significa não somente delimitar o que ele é, visto que a partir desta delimitação se define em larga escala o que ele deve ser. Ou seja, qualquer interpretação a respeito do que seja o ser social alagoano não é ingênua, pois está necessariamente vinculada a uma determinada posição no conflito social preponderante, bem como prescreve - mesmo que de forma inconsciente - como deve se dar o devir desta mesma formação social. ${ }^{9}$ Mais a frente nos debruçaremos sobre Théo Brandão para exemplificar esta relação entre identidade cultural e conflito.

Dirceu Lindoso nos mostra que desde a época em que Alagoas ainda era uma comarca da capitania de Pernambuco já havia uma peculiaridade desta região em relação ao norte da capitania. Diz ele:

Há indícios de que no século XVIII o espaço alagoano se apresentava como dotado de um modo diferencial de falar-se o português de origem minhota ou além-tejana; como um aglomerado populacional onde se iniciavam certas formas de distinções de conduta social, de aglutinamento dos elementos culturais; de definição política da organização social em

\footnotetext{
8 Seguindo a lógica de Théo Brandão, poderíamos afirmar que a carroça de propulsão animal - com pneus de fusca e molas de caminhão - que faz parte do cotidiano da capital alagoana se configura enquanto uma reminiscência arcaica, tradicional, que convive numa relação de externalidade com os meios de transporte modernos (carros, motos, etc.). Neste sentido, a carroça também faria parte do que há de mais puro do ser alagoano: seria um exemplo da nossa tradição que não se rende ao movimento da sociedade em vias de modernização. Entretanto, longe de possuir um significado reificado cunhado em suas origens - engenhos coloniais - que nada tem a ver com a nossa modernidade, a carroça é um grande exemplo que demonstra a imbricação entre o novo e o velho do capitalismo alagoano mesmo em sua fase globalizada; longe de ser um anacronismo se configura enquanto um partícipe direto da nossa formação capitalista hiperatrasada na qual o novo e o velho se sintetizam dialeticamente numa totalidade complexa, tendo o velho um caráter predominante.

${ }^{9}$ Esta relação entre a interpretação a respeito do ser com o vir-a-ser é imprescindivel para pensarmos a cultura. Como um conjunto de idéias e valores assentados em uma dada realidade sócio-histórica, a cultura dá sentimento de pertença aos indivíduos de maneira que estes ocupem um dado papel nesta sociabilidade; entretanto, a sociedade não é uma mera reprodução do mesmo, mas se depara com o contínuo jorrar do novo, com o incessante surgimento de necessidades que precisam ser respondidas pelos sujeitos. É neste momento que identidade cultural é fundamental para o vir-a-ser da sociedade, pois as respostas que os sujeitos históricos darão às necessidades oriundas de seu ser social estão em larga escala delimitadas por este conjunto de idéias e valores que chamamos de cultura. 0 homem responde às necessidades históricas de seu ser social escolhendo entre as alternativas inscritas no âmago deste mesmo ser social, sendo a identidade cultural fundamental para estes momentos de tomada de decisão entre alternativas.
} 
aldeias indígenas, povoações, vilas, freguesias, comarcas; de um espaço físico configurado e de referências topográficas nítidas. (LINDOSO, 2005, p. 32) ${ }^{10}$

Ressalta o autor que já no século XVIII essa distinção já se formalizava na escrita, através dos relatórios dos governos de Pernambuco que sempre delineavam a peculiaridade da região sul da capitania. Durante todo o século XVIII há esse processo de gestação da imagem peculiar a respeito do território, da economia, da política e da sociedade da comarca de Alagoas que vai atingir o seu ápice em 1817, data em que o ato régio eleva a comarca ao posto de capitania. A partir do momento em que cessa a sujeição política em relação a Pernambuco é que se dá a "criação de um espaço cultural alagoano, que constitui a materialização da imagem diferencial que se vinha formando numa antecedência de mais de dois século" (Idem, p. 35). Continua Lindoso:

A formação da imagem diferencial das Alagoas, embora constem suas raízes na época colonial, se materializa no Reino Unido, quando se estabelece por decreto régio, a capitania das Alagoas em 1817. A destinação das Alagoas como entidade política de autonomia relativa no corpo do Brasil Reino se prefigura na imagem diferencial que se produz na escrita do século XVIII. (...) Só a partir de 1817 as Alagoas são uma imagem política homogênea e autônoma, que se passa a definir na difícil história social e política do futuro Império (Idem, p. 36).

A partir deste momento é que se inicia o processo de maturação da formação da identidade alagoana, sendo cunhada a partir da ótica dos senhores de engenho e dos comerciantes urbanos. Isso significa dizer que a interpretação a respeito do que seja o ser alagoano durante o séc. XIX é realizada exclusivamente - na escrita e dotada de uma sistematização mínima - por estas camadas sociais hegemônicas econômica e politicamente. "A imagem diferencial se materializa, e se consolida como fato de poder", sintetiza Lindoso.

Antes de prosseguirmos, é fundamental trazer as considerações de Golbery Lessa a respeito desta necessidade de se construir identidades nacionais ou regionais por parte das classes dominantes. Este autor traz no artigo, acima citado, as contribuições do austro-marxista Otto Bauer sobre as construções das identidades nacionais; segundo a sua hipótese, percorrem-se três etapas para se constituir esta identidade nacional ou regional. Sinteticamente, são as seguintes: 1) o momento inicial de erudição no qual uma elite intelectual se debruça sobre o passado histórico e cultural de um povo para daí propor uma interpretação sobre esta peculiaridade; 2) no momento intermediário, um conjunto de agitadores culturais e políticos buscam propagar aquela interpretação da identidade, buscando relacioná-la às instituições políticas para que também se tornem propagadoras da mesma; 3 )

\footnotetext{
10 Citação extraída do livro Interpretação Da Província - Estudos da Cultura Alagoana, especificamente do artigo Representação Social na escrita da cultura alagoana no século XIX, pg. 32.
} 
por último, aquela interpretação da identidade nacional ou regional é assimilada pelo conjunto da população de um dado espaço geográfico, tornando-se partícipe do senso comum o que contribui para a formação da unidade nacional e a soberania do Estado-nação. ${ }^{11}$

Podemos dizer que para as classes dominantes de Alagoas do século XIX também era de suma importância se cunhar uma dada identidade sobre o ser alagoano, devendo esta ser universalizada com o objetivo de reiterar a hegemonia econômica e política constituída. Tal identidade que anseia preservar as relações de classe da província busca apagar as ações contra-hegemônicas de segmentos da classe explorada, tal como a Guerra dos Cabanos de 1832 que é abstraída da identidade do povo alagoano. 0 que se observou foi uma imputação criminal a esta revolta que não estava em conformidade com a natureza do alagoano, sendo supostamente proveniente de seres desprovidos do espírito alagoano. Estavam em consonância com o espírito alagoano aqueles sujeitos que não questionassem a sociedade escravista, baseada na produção agro-exportadora de cana de açúcar, o Estado liberal-escravista e seus senhores de engenhos.

É importante salientar que o Instituto Histórico e Geográfico Alagoano foi um dos primeiros do país, datando de 1862, o que demonstra que a elite aristocrático-mercantil do Estado desde cedo teve a preocupação de elaborar a sua interpretação da história da província. Afora isso, Dirceu Lindoso demonstra minuciosamente que a própria interpretação da província vai sendo modificada, modernizada relativamente, à medida que o capital mercantil vai se sobrepujando ao capital agrárioexportador; passa-se a identificar nos escritos a necessidade de modernização dos engenhos mediante a adoção das modernas usinas, a necessidade de políticas que incentivassem a indústria têxtil do Estado, a crítica à estrutura burocrático-autoritária do Império em favor do liberalismo econômico, entre outros aspectos que demonstram que no interior da própria elite alagoana havia divergências relativas ao futuro da província.

No início do século XX, Alagoas já havia sentido internamente um processo considerável de modernização capitalista, seja através da intensificação do comércio - principalmente em Maceió - ou do surgimento das primeiras indústrias têxteis que intensificavam ainda mais a vida urbana - sendo Fernão Velho e Rio Largo os principais focos. Aliando esse movimento interno é de suma importância considerarmos processos regionais, nacionais e internacionais que ocorriam concomitantemente e que influenciam consideravelmente a realidade local e os sujeitos históricos aqui existentes.

Todo esse cenário sócio-econômico do Estado se irradiava sobre diversos complexos sociais: na política, a sobrepujança do capital mercantil intensificou o processo de urbanização e de modernização da produção de cana de açúcar através das substituições dos banguês, mesmo que a contragosto dos senhores de engenhos - este processo de modernização da política se concretizaria

11 Conferir em Outra Alagoanidade. 
em 1912 com a queda da oligarquia Malta, que é substituída por uma outra oligarquia de caráter mais progressista, modernizante; na cultura, à medida que novos sujeitos emergiam neste processo proletariado urbano, setores médios ligados à burocracia estatal republicana, entre outros - a formulação da identidade alagoana foi sendo transformada, modernizada, seja por parte da perspectiva conservadora, republicano-democrática ou mesmo socialista.

Justamente por isso surgem figuras como Otávio Brandão com seus escritos anarquistas, Graciliano Ramos na literatura, a Escola de Viçosa com seus estudos folclóricos, Arthur Ramos ${ }^{12}$ e os seus estudos sobre os índios, negros e mulheres - que rompem com a abordagem tradicionalmente racista da interpretação da classe dominante alagoana sobre a alagoanidade - , além da modernização na historiografia com Craveiro Costa e Moreno Brandão. Esse processo de transformação da realidade social e do discurso sobre a mesma prosseguiu até 1930 quando se deu a vitória do tenentismo, responsável pela potencialização deste processo modernizante dentro das limitadas capacidades do capitalismo brasileiro.

As transformações vivenciadas nas relações de produção se configuram enquanto o momento predominante que exigiram dos sujeitos históricos respostas imprescindíveis para a reprodução social; a interpretação da identidade é certamente uma resposta a esta necessidade oriunda do trabalho e que passa a compor a totalidade social.

As propostas identitárias para o ser alagoano se tornam mais numerosas a partir do século XX em função do já referido surgimento de novos sujeitos e do espaço extremamente débil, mas existente, da democracia nos perímetros urbanos. Como dito anteriormente, cada uma dessas interpretações não se limitam a representar sobre o que é o ser alagoano, mas trazem consigo uma necessária projeção acerca do que deve ser este ser alagoano.

Todos esses comentários historiográficos são imprescindíveis para situarmos Théo Brandão historicamente. Não podemos defini-lo como um mero folclorista, por mais que fosse assim que ele se identificasse, mas ele "foi um dos contemporâneos mais ativos na construção de uma consciência da alagoanidade". ${ }^{13}$ Atuou ativamente na elaboração de uma identidade alagoana que representasse uma modernização da interpretação aristocrático-burguesa até então em voga, ou seja, foi um erudito capaz

\footnotetext{
12 Podemos dizer que há em Arthur Ramos uma modernização mais progressista do que a existente em Théo Brandão. Para este último, a "essência alagoana" contida no folclore era uma amálgama decorrente da posição simétrica - equitativa - das três matrizes culturais basilares da nossa formação: a africana, a indígena e a portuguesa; ao que nos parece, há nesta abordagem a diluição da relação assimétrica baseada no domínio econômico, político e cultural da matriz portuguesa representada nos senhores de engenho. Já em Arthur Ramos, parece-nos que as relações de poder existente entre as matrizes culturais são reconhecidas e não dissolvidas em um suposto resultado final - 0 folclore; tanto o é que Arthur Ramos se incumbiu de realizar interpretações sobre o negro e o índio que explicitassem tais dominações e que servissem de base para políticas públicas específicas que reconhecessem a discrepância histórica.

13 Outra Alagoanidade, Golbery Lessa.
} 
de perceber o movimento de seu tempo e a partir daí realizar esta atualização indispensável para que a identidade alagoana propagada pela elite local se tornasse plausível.

O homem é um ser que dá respostas e estas são dadas a partir do momento em que as necessidades surgem na realidade social; no caso de Théo Brandão, as transformações existentes na realidade alagoana - assim como os discursos mundiais já existentes sobre o humano - 0 impeliram à dar respostas palatáveis sobre o ser alagoano do ponto de vista de sua classe de origem ${ }^{14}$. Uma série de outros alagoanos também realizaram esta empreitada em outras dimensões (do ponto de vista da elite local), como Moreno Brandão na historiografia, Arthur Ramos na antropologia, que traziam à tona uma série de interpretações até então obscurecidas pela abordagem tradicional da classe dominante, além de Manuel Diegues Jr. que faz uma interpretação modernizada dos banguês alagoanos.

Gilberto Freyre se configura enquanto um marco divisor de águas que influenciou toda uma geração subsequente: não havia mais como tematizar a identidade excluindo o negro e o índio que se tornam partícipes indispensáveis para sua efetivação; entretanto, estes são trazidos para o discurso dominante mediante uma atenuação da trágica relação efetivamente existente, bem como por uma bestialização destes sujeitos historicamente dominados.

Théo Brandão enquanto intelectual orgânico ${ }^{15}$ da elite agrário-mercantil alagoana não pode trazer as camadas populares para o debate político, não pode equipará-las à elite dentro de um projeto transformador de caráter popular-democrático tal como ocorreu na França revolucionária. Lá, os trabalhadores e os camponeses foram chamados pela burguesia para agirem enquanto sujeitos históricos e colocarem a baixo o velho regime, instaurando a modernidade capitalista alicerçada nos ideais de igualdade e liberdade. 0 distanciamento da burguesia em relação às camadas populares já havia sido evidente na Alemanha e na Itália, onde a debilidade da burguesia impedia que ela se contrapusesse revolucionariamente à velha aristocracia feudal, além do que a incapacidade do capitalismo em efetivar os ideais humanistas alardeados durante a revolução francesa abrira espaço para projetos societais que questionavam a ordem do capital, causando temor por parte das burguesias nacionais ainda ávidas por poder político.

\footnotetext{
14 O fato de Théo Brandão ter estudado a identidade alagoana a partir do ponto de vista de sua própria classe não significa dizer que esta relação seja absoluta, inexorável. Afinal, ícones do pensamento do proletariado como Marx, Engels, Lênin, Trotsky e Lukács não faziam parte desta classe propriamente dita, mas abandonaram o ponto de vista de suas classes de origem e assimilaram o ponto de vista do trabalho para pensar a realidade social em que viviam. Michel Löwy nos mostra que alguns intelectuais da pequena-burguesia e até da própria burguesia assumem o ponto de vista da classe trabalhadora por serem sensíveis à antinomia existente entre o capitalismo e os valores humanistas propagados pela própria burguesia revolucionária. Instalada essa "crise" de identidade nestes sujeitos, abrem-se dois caminhos a serem escolhidos por eles: por um lado, o da crítica irracionalista-romântica ao realmente existente que conduz a um pensamento místico como forma de superar a angustia existencial; e por outro lado, a opção da crítica do ser social burguês a partir da ótica do trabalho, que conduz a uma crítica profunda do capitalismo ao mesmo tempo em que se torna claro a possibilidade do vir-a-ser histórico impulsionado pela classe trabalhadora.

15 Termo cunhado por Gramsci em Os Intelectuais e a Organização da Cultura.
} 
A intitulada via prussiana, por Lênin, ou a revolução passiva ou transição pelo alto, por Gramsci, significa precisamente esta transição para o capitalismo em que as massas são apartadas do processo histórico, justamente porque a burguesia quer vê-las distante do poder como forma de impedir que elas ponham as suas demandas a serem efetivadas; instaura-se nesses países instituições muito mais autoritárias, chauvinista, um capitalismo no qual a intervenção estatal é uma constante à medida que eles estão retardados no processo de acumulação de capital, em suma, não há a emergência de uma democracia liberal burguesa. Todos esses problemas decorrentes da via prussiana ao capitalismo existem na transição ao capitalismo pela via colonial, mas tais problemas assumem nestes países um caráter muito mais nocivo, como é o caso do Brasil.

Evidenciamos um processo muito mais acentuado de apartamento das camadas populares das tomadas de decisão, o que fica claro nos processos de independência e de proclamação da República: o distanciamento destes para com a massa é gritante, quase que absoluto. Há também um fortalecimento ainda maior do Estado sobre a sociedade civil com o objetivo frustrado de realizar a modernização capitalista no país a partir da acumulação do capital nacional; entretanto, essa transição hipertardia do capitalismo impede a acumulação do capital nacional que se torna sócio minoritário do capital monopolista dos países centrais.

Ao receio das camadas populares por parte da burguesia nacional, esta fundamenta acordos com as oligarquias agrárias de maneira que os avanços progressistas do capitalismo sejam inexistentes ou limitados, fortalecendo o chauvinismo em detrimento da participação popular. Sobre essa transição diz Carlos Nelson Coutinho:

\footnotetext{
Neste tipo de transição, as camadas subalternas manifestam-se através de um "subversivismo esporádico e elementar" (a expressão é de Gramsci), ao passo que as classes dominantes reagem a esses embriões de um movimento que vem de baixo precisamente com manobras pelo alto, que implicam um acordo e uma conciliação entre os segmentos "modernos" e os segmentos "arcaicos" dessas classes. Não se tratam, essas transições, de meras contra-revoluções, mas são precisamente aquilo que Gramsci chamou de "revoluções-restaurações", ou "revoluções passivas", que, ao mesmo tempo em que se introduzem novidades, conservam muitos elementos da velha ordem. A especificidade deste tipo de transição é precisamente esta: que o novo surge na história marcado por uma profunda conciliação com o velho, com o atraso. (COUTINHO, 2006, p. 144).
}

Essa panorâmica sobre as formações capitalistas é importante para compreendermos a forma positivista como Théo Brandão traz o povo para a interpretação da identidade alagoana. As transformações sociais exigem a atualização desta identidade cunhada pela elite agro-mercantil do estado de forma que Théo Brandão retire as camadas populares do ostracismo, emergindo-as no discurso dominante como sujeitos passivos, inertes e impossibilitados de fazer a sua própria história. Diz Golbery Lessa: 


\begin{abstract}
Primeiro: o homem do povo - que ele gosta de chamar o homem "folk" - não é visto nunca como o protagonista de sua própria história, ou de seu futuro, de seu devir. 0 homem folclórico é visto sempre por Theo Brandão como aquele homem que está apartado da modernidade, que não é e nem pode ser um cidadão, que não é um potencial revolucionário, que não pode ser um potencial protagonista de projetos políticos e propostas globais para a sociedade. 0 homem folclórico é idealizado romanticamente como um homem de necessidades básicas, um homem que não se revolta, um homem que aceita a vida como ela é e que mesmo assim com todas essas limitações reproduz o "espírito" mais profundo de Alagoas - nos seus folguedos, nas suas danças, na sua literatura oral, na sua arte de fazer brinquedos, na sua arte de confeccionar objetos populares . É uma visão paternalista desse homem; é uma visão que isola esse homem da modernidade, da vida real e do universo político. Eu creio que é uma visão extremamente cruel, extremamente preconceituosa que nega a humanidade ao homem do povo. Ao invés de trazer o homem do povo para o diálogo com o intelectual de classe média, ao invés de respeitar esse homem do povo ele é etiquetado, condicionado dentro de determinados espaços em que ele existe como uma espécie de espécime exótico; 0 exótico que seria fundamental pra determinar a singularidade da identidade alagoana. ${ }^{16}$
\end{abstract}

Essa forma de trazer a massa explorada para o seu discurso revela que a modernização do pensamento da classe dominante é extremamente limitada, tratando-se de um movimento de inovação marcado fortemente - enquanto predominância - pelo velho, ou seja, pela continuidade das tradições preconceituosas que assumem uma nova roupagem. Nada mais é do que a "modernização conservadora" que assola não só o pensamento da elite sobre a realidade, mas é imanente ao próprio movimento verificado na realidade material; o historicamente novo é submisso ao historicamente velho no desenvolvimento capitalista de Alagoas.

À guisa de conclusão, a formação capitalista alagoana bem como a vinculação de classe do autor são os elementos que fundamentam a sua absorção da abordagem positivista a respeito do folclore. Os fundamentos básicos da conceituação positivista clássica a respeito do folclore servem bastante ao seu intento: encarar o folclore como uma área específica do saber à medida que possui um objeto sui generis - a civilização tradicional como diz o próprio autor - ; ciência essa que está isenta das explicações causais comuns ao saber científico pelo fato de que seu objeto não possui implicações sociais amplas, pois se trata de anacronismo em relação à modernidade em voga.

Estes aspectos estão em consonância com o objetivo de Théo Brandão de atualizar a imagem da classe dominante alagoana sobre o estado, pois: 1) a cultura popular (folklore) por está apartada da modernidade é entendida como uma dimensão da sociedade carente de autonomia, composta por sujeitos passivos presos à tradição, residindo nela, ao mesmo tempo, o "espírito alagoano" que é generalizado a toda Alagoas e universalizado no tempo, fundamentando-se uma visão paternalista sobre o homem do povo; 2) por se tratar de anacronismo cultural, o folclore não deve ser encarado como uma dimensão de grande importância explicativa à realidade social existente, cabendo apenas a

${ }^{16}$ Citação retirada da entrevista realizada pelo bolsista CNPQ/PIBIC Gabriel Magalhães Beltrão durante a pesquisa de iniciação científica que se coadunou no presente artigo. 
sua descrição e a busca por suas origens por parte dos folcloristas; ou seja, o folclore está isento das contradições que permeiam o mundo moderno, sendo um espaço onde não há conflito, mas sim harmonia típica do "espírito alagoano". Diz Golbery Lessa sobre essa carência de teorização:

\footnotetext{
Eu creio que, a partir da perspectiva de Théo Brandão, teorizar muito sobre o homem folclórico alagoano implicaria em uma série de antinomias, ficaria mais explícitos todos os defeitos que eu sublinhei anteriormente. Ou seja, não teorizar - não sei se ele tinha isso consciente ou inconsciente - implicava em esconder essas várias antinomias éticas e teóricas que a abordagem dele do folclore alagoano possui. ${ }^{17}$
}

Esta imagem sobre Alagoas proposta por Théo Brandão foi acatada por nossa elite local pelo fato de que satisfazia ao seu interesse, visto que a sua definição da identidade alagoana se coadunava com a prospecção que esta tinha em relação ao futuro do estado. Isso não desconsidera a existência de frações conflitantes no interior da elite alagoana, mas reconhece que a proposta de Théo Brandão expressa uma interpretação da identidade alagoana bastante plástica, capaz de angariar concordância seja na fração da elite mais relacionada ao capital mercantil-industrial, seja naquela parcela agroexportadora que reconhece o processo modernizante como inelutável - mesmo que não seja capaz de fazer cessar o sentimento nostálgico dos bangüês alagoanos.

\section{REFERÊNCIA BIBLIOGRÁFICA}

1. BRANDÃO, T. Folclore de Alagoas. Maceió, 1949.

2. Reisado Alagoano. Maceió, 1953.

3. Artigo Influencias Africanas no Folclore Brasileiro.

4. COUTINHO, C. N. Intervenções: o marxismo na batalha das idéias - São Paulo: Cortez, 2006. pg.144

5. FERNANDES, F. 1920-1995. O folclore em questãol Florestan Fernandes. $-2^{\mathrm{a}}$ ed. - São Paulo: Martins Fontes, 2003. - (Raízes).

6. GRAMSCI, A. Os Intelectuais e a Organização da Cultura. 1988, 6 a ed. Civilização Brasileira

7. LESSA, G. Outra Alagoanidade extraído do sítio www.novoirisalagoense.blogspot.com .

8. LESSA, S. Notas sobre a historicidade da essência em Lukács extraído no sítio www.sergiolessa.com .

9. LINDOSO, D. Representação Social na escrita da cultura alagoana no século XIX in Interpretação Da Província Estudos da Cultura Alagoana, 2a ed. - Maceió: EDUFAL, 2005.

10. LÖWY, M. A Evolução Política de Lukács. São Paulo: Cortez, 1999.

11. VAISMAN, E. O Problema da Ideologia na Ontologia de G. Lukács. 1986, dissertação. Mimeo.

\section{Artigo recebido em: 15/05/2010 \\ Aceito para publicação em: 18/06/2010}

17 Citação também extraída da entrevista. 
